\title{
Hipertansiyon ve Erektil Disfonksiyon
}

\author{
Hipertansiyon ve Erektil Disfonksiyon
}

\section{Orçun ALTUNÖREN ${ }^{1}$, Ertuğrul ERKEN ${ }^{2}$, Özkan GÜNGÖR ${ }^{1}$, Yasemin COŞKUNYAVUZ ${ }^{3}$}

\author{
${ }^{1}$ Doç. Dr. Kahramanmaraş Sütçü İmam Üniversitesi Tip Fakültesi Nefroloji Bilim Dalı, KAHRAMANMARAŞ \\ ${ }^{2}$ Dr. Öğr. Üyesi. Kahramanmaraş Sütçü İmam Üniversitesi Tip Fakültesi Nefroloji Bilim Dalı, KAHRAMANMARAŞ \\ ${ }^{3}$ Dr. Öğr. Üyesi. Selçuk Üniversitesi Tip Fakültesi Hastanesi Nefroloji Bilim Dalı, KONYA
}

\section{Öz}

Erektil disfonksiyon hipertansif hastalarda sık görülen bir problemdir. Hipertansiyonun kendisi kadar tedavide kullanılan ilaçların da bu probleme katkıda bulunabileceği düşünülmektedir Ancak yaygın inanışın aksine özellikle yeni nesil antihipertansif ilaçlar erektil fonksiyon üzerine olumsuz etkilerde bulunmamaktadır. Hipertansif hastalarda erektil disfonksiyon tedavisinde fosfodiesteraz 5 inhibitörleri güvenle kullanılabilmektedir.

Anahtar Kelimeler: Erektil disfonksiyon, Fosfodiesteraz 5 inhibitörü, Hipertansiyon

\section{GİRIŞ}

Cinsel ilişki için yeterli ereksiyonun sürdürülememesi olarak tanımlanan erektil disfonksiyon (ED) yaşla birlikte sıklı̆̆ı artan bir problemdir. Özellikle 50 yaş üstünde görülme sıklığ 1 artarken hipertansif hastalarda, obezlerde, diyabetik hastalarda, antidepresan veya beta bloker kullanan hastalarda ve sigara içicilerinde çok daha sık görülmektedir (1). Erektil disfonksiyonun hipertansif bireylerde hipertansif olmayanlara göre daha sık görüldüğü kanıtlanmış bir gerçektir. Yine veriler antihipertansif tedavi alan hastalarda (\% 40,4) almayanlardan (\% 19,8) daha sık ED görüldügünü göstermektedir (2-5). Hipertansiyonun kendisi erektil disfonksiyona yol açabildiği gibi kullanılan medikasyonlar ve kan basıncının düşmesine bağlı olarak genital organlardaki perfüzyon yetersizlikleri de patogenezde rol oynamaktadır. Hipertansiyon anjiotensin 2 gibi vazokatif maddeler, endotel disfonksiyonu ve uzun süreli yüksek kan basinci maruziyeti sonucu penil arterlerde yapisal ve fonksiyonel değişikliklere yol açarak patogenezde bizzat rol oynar.

\section{HİPERTANSİF HASTADA ED PATOGENEZI}

ED vasküler orjinli bir problemdir. Penil endotelyal yatak periferik vasküler sistemin özelleşmiş bir uzantısıdır. Normal homeostazı sürdürmeye yönelik uyarılara diğer vasküler sistemler gibi cevap verir (6). Penis, oksidatif strese ve sistemik Nitrik Oksit (NO) seviyelerine duyarlı vasküler bir organdır. Dolaşan nörotrasmitterler, hormonlar ve endotel kaynaklı faktörler vasküler düz kas tonusunu düzenler. Hipertansif hastalarda bu faktörlerdeki değişiklikler vasküler kontraksiyona yol açar. Tüm bunlar ED’nin hipertansif hastalarda daha sık görülmesini açıklamaktadır. Bunun dışında

$\begin{array}{ll}\text { İletişim: } & \begin{array}{l}\text { Dr. Orçun Altunören, KSÜ Tip Fakültesi Nefroloji Bilim } \\ \text { Dalı, Kahramanmaraş }\end{array} \\ \text { DOI: } & \mathbf{1 0 . 1 7 5 1 7 / k s u t f d . 4 7 7 5 1 1}\end{array}$

\section{Abstract}

Erectile dysfunction is a common problem which is seen among hypertensive patients. It is thought that medications used in treatment of hypertension may contribute this problem as well. Contrary to common belief, new generation drugs doesn't produce adverse effect on erectile function. Phosphodiesterase 5 inhibitors can be used safely in treatment of erectile dysfunction in hypertensive patients.

Key Words: Erectile dysfunction, Phosphodiesterase 5 inhibitor, Hypertension

aterosklerozdan penil damarlar da sistemik damarlar gibi etkilenir. Bu nedenle ED sadece ateroskleroz ile birlikte görülmekle kalmayıp aterosklerozu da şiddetle predikte eden bir durumdur (7).

\section{ED ve hipertansiyonda vazokonstrüktör mad- deler:}

\section{Anjiotensin II (AT II):}

AT II, renin-anjiotensin-aldosteron sisteminin bir parçası olan kuvvetli vazokonstüktör özelliklere sahip bir peptittir. Sistemik kan basıncının düzenlenmesinde önemli role sahiptir. AT II seviyelerinin yüksek olması tuz retansiyonu yanında vasküler tonusu da artırarak hipertansiyon patogenezinde rol alır. AT II erektil disfonksiyonun patogenezinde önemli rol oynamaktadır. Bazı çalışmalarda sistemik AT II seviyelerinin ED'li erkeklerde yüksek olduğu gösterilmiştir. ED’si olan hastalarda kavernöz kanda sağlıklı kişilere göre AT II seviyeleri yüksek saptanmıştır $(8,9)$. AT II bu etkilerini AT1 ve AT2 reseptörleri üzerinden göstermektedir. AT 2 reseptörlerinin uyarılması vazodilatasyona AT1 reseptörlerinin uyarılması ise vazokonstrüksiyon, vasküler düz kas hücre proliferasyonu, inflamasyon ve sempatik aktivasyona yol açar. AT1 reseptör blokajının ED'yi düzelttiği görülmüştür (10). AT II penil arter ve kavernöz vasküler düz kas tonusunda artışa yol açar (1112).

\section{Endotelin 1:}

Endotelin 1 de endotelde sentezlenen vasküler tonus üzerine potent konstrüktör etkileri bilinen bir peptittir. ET A ve ET B reseptörleri üzerinden etki

Tel : 05326946517

E-Posta : orcunaltunoren@hotmail.com

Geliş Tarihi : 01.11 .2018

Kabul Tarihi : 16.03 .2019 
eder. Her iki reseptör tipi de kavernöz endotelde tespit edilmiştir (13-16). Peniste kavernöz dokuda ET A reseptörleri yoluyla vazokonstrüksiyona yol açar $(17,18)$ . ET B reseptörlerinin uyarılması ise NO salınımı yoluyla vazodilatör etkilere yol açar (19). Endotelin 1 sadece penil arterde vazokonstrüksiyon yapmakla kalmaz ayrıca penise kan sağlayan major arter olan pudental arterde vazokonstrüksiyon yaptığı da gösterilmiștir $(16,20)$. Endotelin 1 bundan başka NADPH oksidaz aktivasyonu yaparak reaktif oksijen ürünlerini de artırarak endotelde NO sentezini bozar.

\section{Morfolojik değişiklikler:}

Hipertansiyonda diğer damarlar gibi penis damarları da morfolojik değişiklikler gösterir. Duvar kalınlaşması, kollejen birikimi ve lümende daralma görülür (21-22). Hipertansif hayvanlarda tunika albuginea da incelme, elastik liflerde azalma, ve sinüzoidlerde kollejen liflerde artma gösterilmiştir.

\section{3- Erektil Disfonksiyonda vazodilatatör madde- ler:}

ED vazokonstrüktör maddelerin yapımında artma veya bu maddelere duyarlılıkta artma sonucu gelişebildiği gibi vazodilatör maddelerde azalma veya duyarsızlık da söz konusudur. Tüm bunlar endotel disfonksiyonunun klasik bulgularıdır.

\section{Nitrik Oksit (NO):}

Hipertansif hastalarda reaktif oksijen ürünlerinde artış, endotelyal NO sentaz ekpresyonunda azalma gibi sebeplerden dolayı endotel kaynaklı NO düzeylerinde azalma görülür (23-26). Hipertansiyonda oksidan ve antioksidan dengesi bozulmuştur. Reaktif oksijen ürünleri aterogenezde olduğu gibi birçok endotel ilişkili hastalıkta önemli rol oynamaktadır. Rekatif oksijen ürünleri NO'i peroksinitrite dönüştürür. Peroksinitrit, NO’e göre daha zayıf ancak yavaş ve uzun süren bir endotel gevşemesi yapar ve inefektif gevşeme sonucu ED oluşur (27-29).

\section{Hidrojen sülfid (H2S):}

H2S sistatyonin B sentaz (CBS) ve sistatyoninliyaz(CLY) enzimleriyle L-sisteinden oluşur. Eksikliği hipertansiyona katkıda bulunabilir. CLY’nin ilaçlara sekonder ya da genetik olarak inhibisyonu endotel relaksasyonununda bozulma ve hipertansiyona yol açablir (30). Her iki enzim de penil arter ve korpus kavernozumdaki düz kas hücrelerinde gösterilmiştir. Exojen H2S verilmesiyle kavernöz dokuda doza bağlı relaksasyon gösterilmiştir (31). Yine de henüz H2S'in hangi mekanizmalarla erektil fonksiyona katkıda bulunduğu netlik kazanmamış bir konudur.

\section{EREKTIL DİSFONKSIYYON VE ANTİHIPPER- TANSİF İLAÇLAR}

Kardiyovasküler ilaçların erektil disfonksiyon yaptığına dair yaygın bir inanış mevcut olsa da mevcut veriler bunun böyle olmadığı, birçok ilacın erektil disfonksiyon üzerine olumlu etkileri olduğunu göstermektedir. Bu konuda özellikle eski beta blokerler ve tiyazid diüretikler suçlanmaktadır. Gözlemsel çalışmalardan elde edilen verilerde beta bloker ve diüretik almakta olan hastalarda ED daha fazla görülmekteyken anjiotensin konverting enzim (ACE) inhibitörleri, kalsiyum kanal blokerleri ve anjiotensin reseptör blokerleri'nde (ARB) bu durum gözlenmemiştir (4). 1007 hastanın alındığı gözlemsel bir çalışmada en yüksek ED oranımetoprolol (\%49) vekarvedilol'de(\%52) gözlenmiştir (32). Hipertansif hastalarda ED'yi değerlendirmek için özel olarak dizayn edilmiş büyük ölçekli çalışmalar mevcut değildir. Hipertansiyon ve erektil disfonksiyon ilişkisi spesifik olarak ED’ye yönelik yapılmamış olan bazı çalıșmalardan elde edilmiștir (TOMHS, MRC, TAIM, ALPINE) (33-36). Sadece MR-NOED çalışması özellikle hipertansiyonda ED değerlendirmek için dizayn edilmiş olup nebivolol'ün ED'yi düzeltici etkileri olduğunu göstermiștir (37). TOHMS çalışmasında 5 grup antihipertansif ilaç karşılaştırılmış ve özellikle klortalidon ilk 24 ayda erektil disfonksiyonla ilişkili bulunmuşken çalışmanın 48. ayında bu ilişkinin ortadan kalktığı ve diğer ilaçlardan farklı olmadığı görülmüştür. MRC ve TAİM çalışmalarında diüretiklerin ciddi manada ED üzerine olumsuz etkileri görülmüş, beta blokerler ise diüretikler ile plasebo arasında yer almıştır. Beta blokerler üzerinde tartışma devam etmektedir. Beta blokerler intrinsik sempatomimetik aktivite, vazoaktif özellikler ve adrenerjik reseptörlere selektivite farklarıyla heterojen bir grup ilaçtır. Nebivolol, karvedilol ve labetolol vazdilatör etkilere sahiptir. ED patogenezinde vazokonstrüksiyon da bulunduğundan bu grup ilaçların olumlu etkileri olacağı beklenmekteyse de bu tam olarak doğru değildir. Örneğin karvedilol'ün eski beta blokerler gibi ED üzerine olumsuz etkileri görülmüştür. Bu konuda yapılmış iki çalışma (38-39) aslında beta blokerlerin olumsuz etkili olmadığını ve bu olumsuz etkilerin plasebo ile azaldığını göstermiş ancak Fogari tarafından yapılmış 3 randomize çalışmada (40-42) beta blokerlerin ED üzerine olumsuz etkileri sağlam verilerle gösterilmiştir. VA coopertaive çalışmasında ise plaseboyla kıyaslandığında beta bloker, hidroklorotiyazid, kalsiyum kanal blokerleri ve ACE inhibitorleri erektil disfonksiyon insidansında artışa yol açmamış hatta düzelmeler göstermiştir (43). Başka bazı çalışmalarda ise santral etkili alfa antagonistler diğer gruplardan farklı olarak erektil disfonksiyonla iliş̧ili bulunmuştur $(40,44)$. Hipertansif ratlarda ACE inhibitörleri ve nebivolol ED üzerine olumlu etki gösterirken kalsiyum kanal blokerleri ve atenolol herhangibir etki göstermemiştir (45). Yakın zamanda yayınlanan ONTARGET/TRANSCED çalışması (46) ACE inhibitörleri ve ARB lerin ED üzerine etkileri ile ilgili önemli bulgular sağlamıştır. 1549 hastanın değerlendirildiği çalışmada ED prevalansı yüksek riskli hastalarda $\% 55$ bulunmuş, hastalar telmisartan, ramipril, bunların kombinasyonu ve plasebo gruplarına randomize edilmiştir. ONTARGET ve TRANCEDENT çalışmasında ilaç grupları arasında fark bulunmamış ve tedavi sonrasında başlangıca göre ED'de kötüleşme olmamıștır. Ancak bu çalışmalarda ACE inhibitörü ve ARB ler beta blokerlerin de olduğu çoklu antihipertansif alan hastalara eklenmiş olup sonuç olarak ACE inhibitörü ve ARB lerin ED üzerine olumlu etkileri olduğunu söylemek için yeterli kanıt yoktur. Yukarıda özetlenen veriler sşı̆̆ında özetle 
eski nesil antihipertansif ilaçlar, özellikle geleneksel beta blokerler ve tiyazid diüretiklerin ED üzerine olumsuz etkileri olduğu kanıtlanmış olup, ACE inhibitörü, ARB ve Nebivolol gibi yeni nesil antihipertansif ilaçların ED üzerine nötr hatta olumlu etkiler göstermekte olduğu söylenebilir.

Hipertansiyon tedavisinde etkinliği bilinen non farmakolojik tedavinin erektil disfonksiyon üzerine de olumlu etkileri olabilir. Fiziksel olarak aktif hastalarda erektil disfonksiyon sıklığı daha düşük olmaktadır. Kilo vermenin obes bireylerde erektil disfonksiyonda anlamlı derecede düzelme sağladığı gösterilmiştir (47). Benzer şekilde hipertansif hastalarda düzenli egzersiz programının erektil disfonksiyona olumlu yönde katkı sağladığı gösterilmiştir (48-50). Gupta ve ark’nın yapmış olduğu metaanalizde yaşam tarzı değişikliklerinin IIEF (International Index of Erectile Function-Uluslar aras1 Erektil Disfonksiyon İndeksi) skorunda anlamlı artış sağladığı gösterilmiştir (51).

Hipertansif hastalarda ED tedavisinde erektil disfonksiyon bir antihipertansif ajan başlandıktan sonra başlamışsa başka bir gruptan antihipetansif ajana geçilmesi düşünülebilir. Antihipertansif tedavi ile birlikte fosfodiesteraz 5 inhibitörleri (PDE 5) kullanilabilmektedir. Erektil disfonksiyon hipertansiyon ilaçlarına uyumsuzluğun en önemli nedenlerinden biri olması nedeniyle PDE 5 inhibitörleri antihipertansif tedaviye uyumu da artırmaktadır (52). Ancak bu ilaçları kullanırken dikkat edilmesi gerekli hususlar iyi bilinmelidir. PDE 5 inhibitörleri doğrudan kardiyovasküler sistem üzerine olumsuz etki etmese de cGMP üzerinden periferik vazodilatasyona neden olarak hipotansiyon ve ölümcül ilaç etkileşimlerine yol açabilirler. Sağlıklı genç erkekler de Sildenafil'in kan basıncında ortalama sistolik $8,5 \mathrm{~mm}$ hg diyastolik 5,5 $\mathrm{mmHg}$, Verdanafil'in ise sirasiyla 8 ve $7 \mathrm{mmHg}$ düşüşe yol açtı̆̆1 gösterilmiştir (53). Özellikle alfa adrenerjik bloker ilaçlarla birlikte alındığında ciddi hipotansiyon görülebileceğinden iki ilaç arasında en az 6 saat ara olmasina dikkat edilmelidir. Yine PDE 5 inhibitörlerinin kan basinci 90/60 mmHg altında olan hastalarda kullanılmaması gerektiği unutulmamalıdır. Nitrat türevi ilaçlar PDE 5 inhibitörleriyle birlikte kullanıldığında ölümcül hipotansiyon gelişebilir. Nitrat kullanan hastalarda PDE 5 inhibitörü kullanılacaksa nitratların kesilmesi, başka bir antianjinal ilaç kullanılması ve PDE 5 inhibitörünün ortalama $24-48$ saat sonra kullanılması önerilir (54).

\section{SONUÇ}

Erektil disfonksiyon hipertansif hastalarda sik görülen bir problem olup hayat kalitesini bozmasının yanında tedaviye uyumu da azaltan bir faktördür. Hipertansiyon tedavisinde kullanılan ilaçların erektil disfonksiyona yol açtığ ${ }_{1}$ düşüncesi özellikle yeni nesil ajanların kullanıma girmesiyle birlikte günümüzde geçerliliğini kaybetmiş gibi görünmektedir. PDE 5 inhibitörleri tedavide güvenilir ve etkin bir çözüm olup antihipertansif tedaviye uyumu da artırmaktadır.

\section{KAYNAKLAR}

1. Bacon CG, Mittleman MA, Kawachi I, Giovannucci E, Glasser DB, Rimm EB. Sexual function in men older than 50 years of age: Results from the Health Professionals Follow-Up Study. Ann Intern Med 2003;139:161-8

2. Doumas M, Douma S. Sexual dysfunction in essential hypertension: myth or reality? J Clin Hypertens. 2006;8: 269-74

3. Douma S, Doumas M, Tsakiris A, Zamboulis C. Male and female sexual dysfunction: Is hypertension an innocent bystander or a major contributor? Rev Bras Hypertens. 2007;14: 139-47

4. 4. Doumas M, Tsakiris A, Douma S, Grigorakis A, Papadopoulos A, Hounta A, et al. Factors affecting the increased prevalence of erectile dysfunction in Greek hypertensive compared with normotensive subjects. J Androl. 2006;27: 469-77

5. Doumas M, Tsiodras S, Tsakiris A, Douma S, Chounta A, Papadopoulos A, et al. Female sexual dysfunction in essential hypertension: a common problem being uncovered. J Hypertens. 2006;24: 2387-92

6. 6. Gratzke C, Angulo J, Chitaley K, Dai YT, Kim NN, Paick JS, et al. Anatomy, physiology, and pathophysiology of erectile dysfunction. J Sex Med. 2010; 7: 445-75.

7. Chew KK, Finn J, Stuckey B, Gibson N, Sanfilippo F, Bremner A, et al. Erectile dysfunction as a predictor for subsequent atherosclerotic cardiovascular events: findings from a linked-data study. J Sex Med. 2010; 7: 192-202

8. Jin LM. Angiotensin II signaling and its implication in erectile dysfunction. J Sex Med. 2009; 6: 302-310

9. Becker AJ, Uckert S, Stief CG, Scheller F, Knapp WH, Hartmann U, et al. Plasma levels of angiotensin II during different penile conditions in the cavernous and systemic blood of healthy men and patients with erectile dysfunction. Urology. 2001; 58: 805-810

10. Yang R, Yang B, Wen Y, Fang F, Cui S, Lin G, et al. Losartan, an Angiotensin type I receptor, restores erectile function by downregulation of cavernous renin-angiotensin system in streptozocin-induced diabetic rats. J Sex Med. 2009; 6: 696-707

11. Comiter CV, Sullivan MP, Yalla SV, Kifor I. Effect of angiotensin II on corpus cavernosum smooth muscle in relation to nitric oxide environment: in vitro studies in canines. Int J Impot Res. 1997; 9: 135-40

12. Ertemi H, Mumtaz FH, Howie AJ, Mikhailidis DP, Thompson CS. Effect of angiotensin II and its receptor antagonists on human corpus cavernous contractility and oxidative stress: modulation of nitric oxide mediated relaxation. J Urol. 2011; 185: 2414-20

13. Saenz de Tejada I, Carson MP, de las Morenas A, Goldstein I, Traish AM. Endothelin: localization, synthesis, activity, and receptor types in human penile corpus cavernosum. Am J Physiol. 1991; 261: 1078-85 
14. Holmquist F, Kirkeby HJ, Larsson B, Forman A, Alm $\mathrm{P}$, Andersson KE. Functional effects, binding sites and immunolocalization of endothelin-1 in isolated penile tissues from man and rabbit. J Pharmacol Exp Ther. 1992; 261: 795-802

15. Dai Y, Pollock DM, Lewis RL, Wingard CJ, Stopper VS, Mills TM. Receptor-specific influence of endothelin-1 in the erectile response of the rat. Am J Physiol Regul Integr Comp Physiol. 2000; 279: 25-30

16. Carneiro FS, Giachini FR, Lima VV, Carneiro ZN, Nunes KP, Ergul A, et al. DOCA-salt treatment enhances responses to endothelin-1 in murine corpus cavernosum. Can J Physiol Pharmacol. 2008; 86: $320-8$

17. Granchi S, Vannelli GB, Vignozzi L, Crescioli C, Ferruzzi P, Mancina R et al. Expression and regulation of endothelin-1 and its receptors in human penile smooth muscle cells. Mol Hum Reprod. 2002;8: 1053-64

18. Wingard CJ, Husain S, Williams J, James S. RhoA-Rho kinase mediates synergistic ET-1 and phenylephrine contraction of rat corpus cavernosum. Am J Physiol Regul Integr Comp Physiol. 2003; 285: 1145-52

19. Ari G, Vardi Y, Hoffman A, Finberg JP. Possible role for endothelins in penile erection. Eur J Pharmacol. 1996; 307: 69-74

20. Allahdadi KJ, Hannan JL, Tostes RC, Webb RC. Endothelin-1 induces contraction of female rat internal pudendal and clitoral arteries through ET(A) receptor and rho-kinase activation. J Sex Med. 2010; 7: 2096-103

21. Jiang R, Chen JH, Jin J, Shen W, Li QM. Ultrastructural comparison of penile cavernous tissue between hypertensive and normotensive rats. Int J Impot Res. 2005; 17: 417-23

22. Behr-Roussel D, Gorny D, Mevel K, Compagnie S, Kern P, Sivan V et al. Erectile dysfunction: an early marker for hypertension? A longitudinal study in spontaneously hypertensive rats. Am J Physiol Regul Integr Comp Physiol. 2005; 288: 276-83

23. Costa C, Virag R. The endothelial-erectile dysfunction connection: an essential update. J Sex Med. 2009; 6: $2390-404$

24. Jin L, Lagoda G, Leite R, Webb RC, Burnett AL. NADPH oxidase activation: a mechanism of hypertension-associated erectile dysfunction. J Sex Med. 2008; 5: $544-51$

25. Feletou M, Kohler R, Vanhoutte PM. Endothelium-derived vasoactive factors and hypertension: possible roles in pathogenesis and as treatment targets. Curr Hypertens Rep. 2010; 12: 267-75

26. Ushiyama M, Kuramochi T, Yagi S, Katayama S. Antioxidant treatment with alpha-tocopherol improves erectile function in hypertensive rats. Hypertens Res. 2008; 31: 1007-113

27. Agarwal A, Nandipati KC, Sharma RK, Zippe CD, Raina R. Role of oxidative stress in the pathophysio- logical mechanism of erectile dysfunction. J Androl. 2006; 27: 335-47

28. Packer MA, Scarlett JL, Martin SW, Murphy MP. Induction of the mitochondrial permeability transition by peroxynitrite. Biochem Soc Trans. 1997 25: 909-14

29. Khan MA, Thompson CS, Mumtaz FH, Mikhailidis DP, Morgan RJ, Bruckdorfer RK, et al. The effect of nitric oxide and peroxynitrite on rabbit cavernosal smooth muscle relaxation. World J Urol. 2001; 19: $220-4$

30. Yang G, Wu L, Jiang B, Yang W, Qi J, Cao K et al. H2S as a physiologic vasorelaxant: hypertension in mice with deletion of cystathionine gamma-lyase. Science. 2008; 322: 587-90

31. d'Emmanuele di Villa Bianca R, Sorrentino R, Maffia P, Mirone V, Imbimbo C, Fusco F, et al. Hydrogen sulfide as a mediator of human corpus cavernosum smooth-muscle relaxation. Proc Natl Acad Sci U S A. 2009; 106: 4513-8

32. Cordero A, Bertomeu-Martínez V, Mazón P, Fácila L, Bertomeu-González V, Conthe P, et al. Erectile dysfunction in high-risk hypertensive patients treated with beta-blockers agents. Cardiovasc Ther. 2010; 28: $15-22$

33. Grimm RH, Grandits GA, Prineas RJ, McDonald RH, Lewis CE, Flack JM, et al. Long-term effects on sexual function of five antihypertensive drugs and nutritional hygienic treatment in hypertensive men and women: Treatment of Mild Hypertension Study (TOMHS). Hypertension. 1997;29: 8-14

34. Medical Research Council Working Party on mild to moderate hypertension, report of 1981 . Adverse reactions to bendrofluazide and propranolol for the treatment of mild hypertension. Lancet. 1981;2: 539-43

35. Wassertheil-Smoller S, Blaufox MD, Oberman A, Davis $\mathrm{BR}$, Swencionis C, Knerr MO, et al. Effect of antihypertensives on sexual function and quality of life: the TAIM study. Ann Intern Med. 1991;114:613-20

36. Lindholm LH, Persson M, Alaupovic P, Carlberg B, Svensson A, Samuelsson O. Metabolic outcome during 1 year in newly detected hypertensives: results of the antihypertensive treatment and lipid profile in a north of Sweden efficacy evaluation (ALPINE study). J Hypertens. 2003;21: 1563-74

37. Brixius $\mathrm{K}$, Middeke $\mathrm{M}$, Lichtenthal A, Jahn E, Schwinger RH. Nitric oxide, erectile dysfunction and beta-blocker treatment (MR-NOED study): benefit of nebivolol versus metoprolol in hypertensive men. Clin Exp Pharmacol Physiol. 2007;34: 327-31

38. Silvestri A, Galetta P, Cerquetani E, Marazzi G, Patrizi R, Fini M. Report of erectile dysfunction after therapy with beta-blockers is related to patient knowledge of side effects and is reversed by placebo. Eur Heart J. 2003;24: 1928-32

39. Cocco G. Erectile dysfunction after therapy with metoprolol: the Hawthorne effect. Cardiology. 
2009;112:174-7

40. Fogari R, Zoppi A, Poletti L, Marasi G, Mugellini A, Corradi L. Sexual activity in hypertensive men treated with valsartan or carvedilol: a crossover study. Am J Hypertens. 2001;14: 27-31

41. Fogari R, Preti P, Derosa G, Marasi G, Zoppi A, Rinaldi $A$ et al. Effect of antihypertensive treatment with valsartan or atenolol on sexual activity and plasma testosterone in hypertensive men. Eur J Clin Pharmacol. 2001; 58: 177-80

42. Fogari R, Zoppi A, Corradi L, Mugellini A, Poletti L, Lusardi P. Sexual function in hypertensive males treated with lisinopril or atenolol: a cross-over study. Am J Hypertens. 1998;11: 1244-7

43. Materson BJ, Reda DJ, Cushman WC, Massie BM, Freis ED, Kochar MS et al. Single-drug therapy for hypertension in men. A comparison of six antihypertensive agents with placebo. The Department of Veterans Affairs Cooperative Study Group on Antihypertensive Agents. N Engl J Med 1993;328: 914-21

44. Della Chiesa A, Pfiffner D, Meier B, Hess OM. Sexual activity in hypertensive men. J Hum Hypertens 2003; 17 : 515-21

45. Manolis A, Doumas M. Antihypertensive treatment and sexual dysfunction. Curr Hypertens Rep. 2012;14: 285-92

46. Böhm M, Baumhäkel $M$, Teo K. ONTARGET/ TRANSCEND Erectile Dysfunction Substudy Investigators. Erectile Dysfunction predicts cardiovascular events in high-risk patients receiving telmisartan, ramipril, or both: the Ongoing Telmisartan Alone and in combination with Ramipril Global Endpoint Trial/ Telmisartan Randomized AssessmeNT Study in ACE iNtolerant subjects with cardiovascular Disease (ONTARGET/TRANCEND) Trials. Circulation. 2010;121:1439-46
47. Esposito K, Giugliano F, Di Palo C, Giugliano G, Marfella R, D'Andrea F, et al. Effect of lifestyle changes on erectile dysfunction in obese men: a randomized controlled trial. JAMA. 2004;291:2978-84

48. Hannan JL, Maio MT, Komolova M, Adams MA, et al. Beneficial impact of exercise and obesity interventions on erectile function and its risk factors. J Sex Med. 2009;6: 254-61.

49. Lamina S, Okoye CG, Dagogo TT. Therapeutic effect of an interval exercise training program in the management of erectile dysfunction in hypertensive patients. J Clin Hypertens. 2009; 11: 125-129

50. Claudino MA, Delbin MA, Franco-Penteado CF, Priviero FB, De Nucci G, Antunes E, et al. Exercise training ameliorates the impairment of endothelial and nitrergic corpus cavernosum responses in diabetic rats. Life Sci. 2011;88: 272-7

51. Gupta BP, Murad MH, Clifton MM, Prokop L, Nehra A, Kopecky SL. The effect of lifestyle modification and cardiovascular risk factor reduction on erectile dysfunction. Arch Intern Med. 2011;171:1797-803

52. Vlachopoulos C, Jackson G, Stefanadis C. Erectile dysfunction in the cardiovascular patient. Eur Heart J. 2013;34: 2034-46

53. Lee M. Focus on phosphodiesterase inhibitors for the treatment of erectile dysfunction in older men. Clin Ther 2011;33: 1590-608

54. Kloner RA, Henderson L. Sexual function in patients with chronic angina pectoris. Am J Cardiol 2013;111:1671-76 